\title{
Effects of "the Selected Smartphone Social-Messaging Applications" Training on Iranian Elderly's Quality of Life: Results of a Qualitative Study
}

\author{
https://doi.org/10.3991/ijim.v15i07.19475 \\ Seyed Ebrahim Hosseini ${ }^{\bowtie}$, Stuart Charters, Patricia Anthony \\ Lincoln University, Canterbury, New Zealand \\ Seyedebrahim.hosseini@lincolnuni.ac.nz \\ Abdulsalam K. Alhazmi \\ University of Science and Technology, Sanaa, Yemen
}

\begin{abstract}
This qualitative study aimed to investigate the effects of using smartphone's communication apps on Quality of Life (QoL) of elderly people living in Shiraz-Iran. The population of the study was all the senior residents registered with local public health centers located in Shiraz, Fars, Iran in 20182019. Overall, 20 participants volunteered to join the study, from the intervention and control groups (10 in each). Data were collected via semi-structured face to face interviews and analyzed using open-coding. The findings of this study and the educational training are intended to help families, practitioners in the aging field to pay more attention to teaching modern communication technology in order to promote healthier elderly and community.
\end{abstract}

Keywords-Iranian elderly; Quality of life; Smartphone; Social applications; Semi-experimental qualitative method

\section{Introduction}

The 21 st century is the century of the elderly. In many countries, the elderly population is rising sharply which necessitates special concern in order to build and promote self-care and increase quality of life (QoL) among seniors[1-4]. The statistics in Iran showed that in 2019 nearly $10 \%$ of a population of 75 million is over 60 years of age[5]

Literature shows that the Iranian population of elderly people have a relatively low QoL compared with other age groups which put emphasis on studies which seek effective action to improve the quality of life among the Iranian elderly people.

Due to the increase in aging population, improving the level of wellbeing and quality of life has recently attracted the attention of many researchers. In Iran, several studies have investigated the effects of different methods and training programs on improving QoL among Iranian elderly people $[5,6]$. 
and as a result, the positive impact of training in different areas of health and social activities on improving well-being and quality of life of the elderly has been proven in several studies [6]

Keeping this background in mind, recently, information and communications technology (ICT) provides a considerable opportunity for enhancing elderly people's lives, allowing them to maintain their independence, have a longer life span and better QoL, all around the world [7] .ICT has certainly become the central driver for the evolution of a modern society[8]. Studies revealed that older people who use modern technologies such as the Internet and smartphones have a higher level of mental health and brain function and are less likely to suffer from diseases such as Alzheimer.

Smartphones remain a relatively new technology with the first smartphone arriving in Iran about 10 years ago in 2010 . The use of mobile devices is increasingly becoming an important part of daily life[9]. Smartphone adoption was quick and within a short period of time it was inextricably linked to millions of Iranians.

On the other hand, despite several proven evidence all around the world, reviewing related studies among Iranian population show that although the positive impact of internet and communication devices usage such as smartphone on improving QoL among elderly has been mentioned in some reports and studies, to date no attempt has been made to study the impact of education or training in smartphone use on quality of life. Major studies that have been conducted have been based on traditional education and traditional activities of old age in Iran.

Although, the internet and smartphone user rates in Iran are seeing a sharp monthly growth, the data and information on the rate of using Internet and smartphone by Iranian elderly is very limited. In addition, the prevalence of internet usage by Iranian elderly, compared to other age groups, is relevantly low; due to several reasons such as rapid technological changes, learning problems, lack of sufficient knowledge about using the Internet and cultural issues [10]. For example, a study among a small population of Iranian elderly people (445 participants) in 2015 revealed that less than 10\% of the participants used the Internet [11].

The main study question of this qualitative study was:

What is the impact of a smartphone training program on the quality of life for Iranian elderly people living in Shiraz?

Based on the researchers' knowledge, this is the first time that specific smartphone use training is implemented among Iranian elderly.

The remainder of this paper is organized as follows. The next section describes the methodology including study design, methods, and instruments in detail. Results are discussed in Section 3, and the paper finishes with the discussion.

\section{$2 \quad$ Methodology}

A qualitative study with an intervention and control group was designed. The study population included all the senior residents registered in local public health centers in Shiraz, Fars, Iran in 2018. Of 17 health centers located in Shiraz, 5 centers which 
provide primary health care for seniors regularly, accepted to join the study. The participants of the study were selected among this population based on the inclusion and exclusion criteria explained below:

Inclusion criteria: Residents aged 60 years old and above who have a smartphone (to make educational tasks possible).

Exclusion criteria: Have been diagnosed or treated for psychiatric illnesses, due to the specific mental and medical conditions/limitations of individuals with psychiatric illnesses; Have mental retardation due to the specific learning conditions/limitations of individuals with mental retardation; Completely familiar with the educational package, based on the gathered information participants and their families.

\subsection{Sampling technique and sample size}

To collect data, a purposive sampling method (homogeneous sampling) was used. In qualitative studies, calculating a representative sample size is not a critical issue, because the value of data was assessed based on saturation. However, for phenomenological studies, the required number of participants depends on the research saturation [12]. Overall, 20 participants (10 in each group) participated in the current study.

\subsection{Training package intervention}

A training package was adapted from previous studies related to internet and communication devices training for elderly people [13-15] . Winstead's educational training package consisted of classifying computer parts and turning off and on the computer, how to use email, web-searching, social networking, and YouTube. Blažun, et. al [14] educational package provided guidance on how to browse and search for numerous information important to the elderly through the internet such as looking for social events, reading newspapers as well as searching for medical information. Sitti and Nuntachompoo's [15] educational package composed of five subjects such as computer introduction, Windows training, Internet and web browser as well as e-mail, using social media such as Facebook and searching information. The educational program was modified to suit the specific requirements of target population, the environment that the participants live in, the local culture, ethnic and religious differences and similarities, special health situation of participants and time limitations.

Based on the results of a study by Navabi et al.[16], 80\% of Iranian adults use mobile phone in which more than $65 \%$ of them are smartphone. Hence, in this study smartphone was used instead of instead of computer. The social media used in this study are free, easy to access, user-friendly, and very popular in Iran. The educational package included three popular applications (Instagram, Telegram, and WhatsApp). Telegram, is the most popular application in Iran for contacting relatives, exchanging news, reporting events and even online shopping in Iran. WhatsApp and Instagram are also popular.

The educational package includes: How to use web browser; How to Search for information and news; Working with Telegram; Working with Instagram; Working with WhatsApp. The training sessions were held 3 times a week (45 min for each session) 
for 3 months. Outside each session, participants were asked to work on additional exercises. For example, they were asked to send each other or researcher text message, or to share photo or a short video.

\subsection{Data collection}

In the first phase of collecting data, all those who were willing to participate in the study and signed the consent form were asked to answer some screening sociodemographic and health questions and their level of familiarity with social/communication smartphone apps. By examining the volunteers' responses to these questions and based on the inclusion and exclusion criteria, the eligible individuals were identified for the study. Overall, 20 eligible volunteers were selected for the study using simple random selection from those eligible to participate. The selected participants were then randomly divided into intervention and control groups (10 in intervention and 10 in control group).

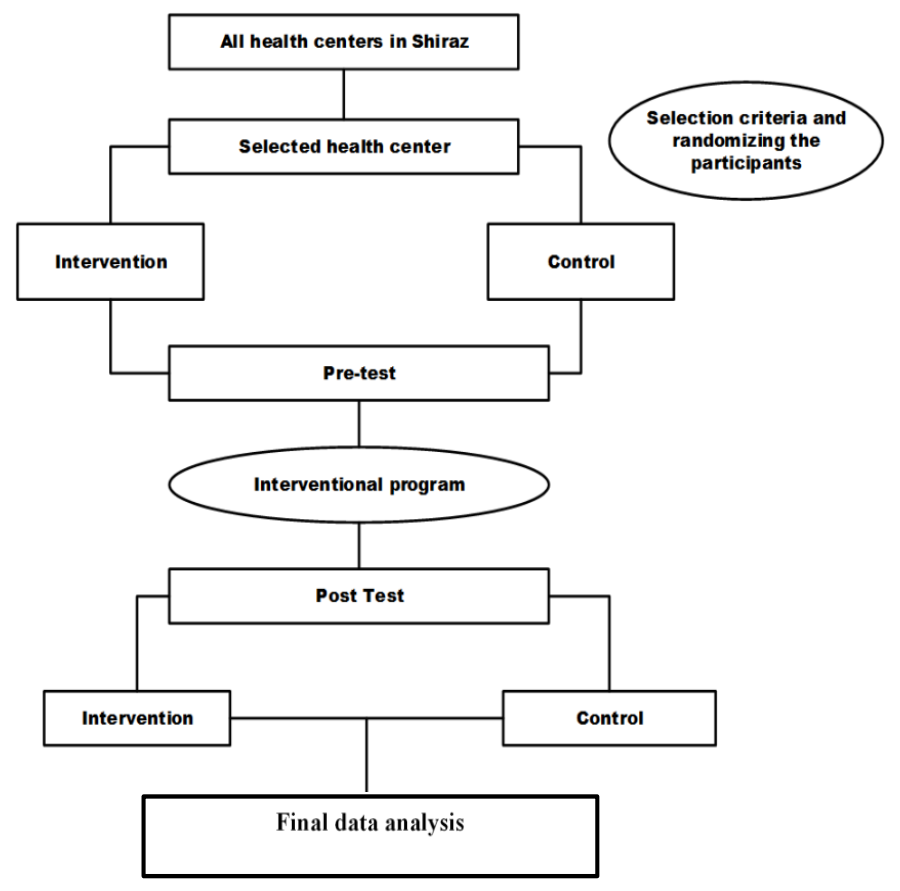

Fig. 1. Data collection and data analysis steps of the quantitative study

For collecting and analyzing participants' experiences, ideas and statements regarding the study questions, the Colaizzi approach was utilized. This qualitative method is "a rigorous and robust method that the researchers used to find, understand, describe and depict the experiences of participants as they experience them" [17] 
First, the researcher described the objective and questions of the study as well as basic concept of QoL based on the WHO's definition. Data collection was conducted through face-to-face semi- structured interviews and field notes (the notes from the researcher's observations). The estimated time for each interview was 20 minutes. The data was processed by extracting and deducing the main statements and keywords. All recordings' data was transcribed on the same day of interviews (Fig. 1).

Only 16 participants participated in the post-test assessments: nine and seven participants in intervention and control groups respectively. One participant in the intervention group and one participant in the control group decided to withdraw from the study and 2 other participants in the control group had health condition. Data was obtained from written texts and recording, in the form of interview. The interview consisted of four questions, two focused around general smartphone use and two focused on the impacts of social media apps:

General Question \#1: Can you tell me about how you started using a smartphone and what tasks you use it for?

General Question \#2: How has your use of a smartphone changed over time?

Core Question \#3: Focusing on the most popular social media application in Iran (Telegram, WhatsApp, and Instagram), what you would think are the negative impacts/limitations of using smartphones?

Core Question \#4: Focusing on the most popular social media application in Iran (Telegram, WhatsApp, and Instagram), what you would think are the positive impacts/advantages of using smartphones?

\subsection{Data analysis}

Credibility, dependability, conformability and transferability are the four criteria introduced by Guba and Lincoln [18] and were used for assuring data trustworthiness and rigor. All statements were translated to English once and then were translated back to Persian by different people to ensure the study credibility. To assure confidentiality, all respondents' personal IDs were removed before the transcripts were coded using open coding [19].

At the end of each interview, the participant was given an opportunity to give their overall opinion and ask questions (if any). Also, they were given a health package information for elderly provided by the health centres. The transcripts were read several times for emergent themes and statements were rechecked in order to create the next level of coding. Data were re-coded by researcher and a trained research assistant by grouping statements. Finally, the original transcripts were checked again to ensure that the context warranted the classification. The whole process enabled participants' experiences to be reflected within themes as much as possible by the researcher [20]. 


\section{$3 \quad$ Result}

The qualitative content analysis focused on themes and codes summarizing the participants' statements at the pre- and post-intervention stages using two coding approaches:

1. Coding statements based on personal, familial, and social considerations.

2. Coding statements based on CASP subcategories (control, autonomy, pleasure, and self- realization).

Table 1. Represents the socio-demographic characteristics of the participants in the intervention and control groups.

\begin{tabular}{|l|c|c|}
\hline & Intervention (\%) & Control (\%) \\
\hline Age (Mean \pm SD) & $66.37 \pm 2.01$ & $66.89 \pm 2.36$ \\
\hline Educational Level & 37.3 & 36.7 \\
Under Diploma & 49.2 & 46.7 \\
Diploma & 10.2 & 10.0 \\
Bachelor & 3.4 & 6.7 \\
Master and upper & 57.6 & 56.7 \\
\hline Gender & 42.4 & 43.3 \\
Male & 25.8 & 28.3 \\
Female & 24.4 & 28.3 \\
\hline Number of Children & 25.8 & 43.3 \\
One child & & 72.3 \\
2-3 children & 75 & 17.6 \\
More than 3 children & 15 & 10.1 \\
\hline Marital Status & 10 & \\
Married & & \\
Widower & & \\
Divorced & & \\
\hline
\end{tabular}

The coding frame includes theme, code, and number/percentages of the occurrence in order to understand the range and magnitude of responses and themes.

\subsection{Pre-test responses}

Answering questions 1 and 2, participants mostly mentioned that one of their family members (mostly children) has chosen/bought their smartphone for them.

"My old phone had broken. So, I asked my son to choose me a new one. Honestly, I do not know anything about buying these new things. He also installed some program on my new phone. But I have rarely used them. It was about one and half years ago". (male participant, 69, intervention group)

"Last year my daughter wanted to change her phone to a new one. Mine was not working well; so, she gave me, or in better words sold me, her old phone and bought a new one. Since then, I have been using her phone. I mostly used it for calling my family members. Sometime, my son sends me my grandchildren photos or videos". (female participant, 68, control group) 
"I bought this phone 6 months ago when my little grandson broke my old one. Regularly, I use it for calling someone. I also have an account in Telegram. My children sometimes send me message. I know how to reply them but nothing more!" (male participant, 69, intervention group).

As the main focus of the study was on smartphone's communication applications, the participants were also asked about what they know about communication apps. Participants' responses to these questions indicated that some of them were unaware of mobile apps. Some participants also considered the use of these applications as a serious risk to traditional and religious beliefs of families, given their traditional beliefs:

"I just know these days, wherever you go, young people just play with their phones. No matter what we say, they don't put it aside for a minute." (male participant, 68, intervention group).

"It seems to me that people are no longer interested in traditional and family celebrations." (male participant, 70, control group)

"In the old days when there were no smartphones, people were more likely to see each other". (female participant, 71, control group)

On the other hand, some of the interviewees believed that this technology could be useful and even fun if used correctly. Along with these two options, some participants believed that the tool might be helpful and harmful, but because they did not know how to do it, they were not sure.

"My son and his grandchildren live abroad. If I want to call them with my cell phone, it costs a lot. Through these programs I talk to them and see their picture. Of course, I don't know myself and my youngest daughter must help me get in touch." (female participant, 72, intervention group)

"I think it's a good opportunity and I would love to learn. But I'm not a very patient person. Furthermore, my son has an excuse every time and most of the time is not home" (male participant, 72, control group)

Overall, most of the participants had an acquaintance with some of the applications, but their viewpoints were very different (Table 2). Based on the participants statements in the interviews, family values, religious beliefs, as well as the number and gender of young people living at home, seemed to influence older people's view of mobile apps (specifically social apps).

Table 2. The number of repetitions of each code, related to question $\# 2$, in intervention( $n=10)$ and control $(\mathrm{n}=10)$ groups in pre-test

\begin{tabular}{|c|l|c|c|}
\hline$\#$ & \multicolumn{1}{|c|}{ Codes } & Intervention n (\%) & Control n (\%) \\
\hline $\mathbf{1}$ & So popular & $10(100)$ & $10(100)$ \\
\hline $\mathbf{2}$ & Sending photo and texts & $7(70)$ & $6(60)$ \\
\hline $\mathbf{3}$ & Source of NEWS & $6(60)$ & $5(50)$ \\
\hline $\mathbf{4}$ & Get youth so busy & $4(40)$ & $4(40)$ \\
\hline $\mathbf{5}$ & Imitate traditional relationships & $7(70)$ & $8(80)$ \\
\hline $\mathbf{6}$ & Good for abroad relations & $4(40)$ & $5(50)$ \\
\hline $\mathbf{9}$ & Seems fun & $3(30)$ & $4(40)$ \\
\hline
\end{tabular}


Regarding the communication apps that participants mentioned in their statements, most respondents pointed the Telegram app, the most well-known social media app in Iran. Instagram and WhatsApp came in second and third, respectively. However, only $5 \%$ of the participants mentioned other apps. Some participants did not remember the name of the applications, instead, they could describe its environment and performance. Fig. 2 represents the summary of the participants' answers in intervention and control groups.

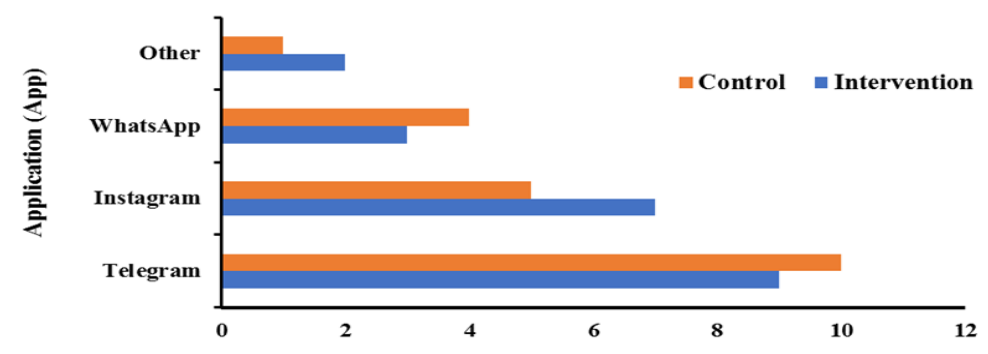

Fig. 2. The communication apps mentioned by the participants in intervention and control groups.

Analysing pre-test data for core questions: The participants' responses to the core questions were analysed twice based on the socio-demographic and cultural factors as well as CASP subcategories (control, autonomy, pleasure and self- realization). The transcripts of the statements were coded twice to cover both sociodemographic/cultural factors and QoL subscales.

Three main themes were defined for socio-demographic and cultural factors, including:

- Theme A: Personal consideration

- Theme B: Family consideration

- Theme C: Social (community) consideration

The participants statements related to these terms were analysed manually and are represented below:

Theme A: Personal consideration in pre-test

Majority of the participants indicated that they think utilizing new technologies such as smartphone apps is late for their age. They mostly pointed to different age limitation as an excuse for not using apps.

"I am old for these new things, let the young ones use them" (a male participant, 68 , intervention group)

"I'd rather read my hardcopy books, these phones just make me confused" (a male participant, 71, control group).

"My eyes are weak for working with these programs. I cannot read the posts" (a female participant, 69, control group). 
"I tried Telegram once or twice. But the trembling of my hands did not allow me to write texts. So, I put it aside" (a male participant, 65, intervention group).

"It is not easy to learn it for someone in my age. I'd rather call others, it's easier" (a female participant, 65, intervention group).

However, as the discussions continued, many participants expressed their interest to use smart phone apps despite their limitations. They believed that using smart phone apps may increase their self-confidence.

"It might be good.... I mean, acting like the younger members in the family" (a male participant, 67, intervention group).

"Now that I think of it, it looks good. I can see photos and videos of my grandson every day without my son's help. So, he cannot boast that I don't have time ...(laughed!)" (a female participant, 66, intervention group).

On the other hand, some participants mentioned that no one in their family has time to teach them how to use the apps by details. So, they have almost stopped trying to learn.

"I think I am a slow learner. Who would want to spend time teaching me? The new generation is not patient at all..." (a male participant, 67, control group).

Theme B and C: Social consideration in pre-test

Along with personal limitations and benefits, participants also addressed issues related to family and community reaction. This part of the discussion involved a complex set of limitations and benefits. Below are examples of interviewees' responses to this.

"My son says: Mom, it is too late for you to have an Instagram [account]. This is for the younger ones ..." (a female participant, 68, control group).

"My husband uses Telegram, but I think he doesn't want me to. You know... Our family is too traditional" (a female participant, 65, control group).

"I think the use of these programs in our society is not very acceptable to older people. The environment of these programs is more suitable for young people" (a male participant, 70, intervention group), and, the positive viewpoints:

"My daughter always says it's better to learn these [the communication apps]. She is studying abroad and believes that using these programs, she can get in touch with us much easier and faster. I think it's time for me to learn [the communication apps] ..." (a male participant, 70, intervention group).

"I have a 12-year-old granddaughter living in another city. She always says if you learn this [Telegram app], we can send each other photos every day!! This is so good because I miss her so much..." (a male participant, 69, intervention group).

Analysing statements based on CASP-19 questionnaire domains (control, autonomy, pleasure, and self-realization): The participants' statements in the pre-test were reviewed once again, this time considering the quality-of-life domains based on CASP-19 questionnaire including control, autonomy, pleasure and self-realization. Five keywords (age limitation, complicated to learn, physical issues, slow learning, better control to life activities) were identified as the closest ones to the control concept. Along with previous examples related to these terms, the following statements from the participants also represent more perspective of their viewpoints: 
"Every time I need to use my Telegram [account], I should ask someone to help me, because I am a little bit confused about it [working with Telegram App] ... ..." (a male participant,67, control group).

"I used my son's account to send a message to my daughter living in another city. But I sent the message to one of his friends by mistake!" (a male participant,72, intervention group).

"My son was not happy about it. He is not happy about using his phone by me at all, and I think he is right. I think if I learn to use it [WhatsApp], I have more control on sending messages....." (a female participant,65, control group).

Age limitation, time limitation, expensive instrument and cultural issues were the keywords related to autonomy. Furthermore, three keywords identified related to pleasure (seems fun, good hobby and easy to communicate). Regarding to autonomy, the statements below could represent the appropriate examples to clear the viewpoints of the participants in pre-test interviews:

"When I asked my son to install Telegram on my [smart]phone, he said my phone was old [version] and not fast enough [its speed is low]. The price of newer phones has also gone up. I also do not know how to work with them very well. So, I just gave up..." (a female participant,66, intervention group).

"I love to learn. But many things must be considered in our age. You can't do anything you want..." (a male participant,69, intervention group).

"I always see young people are too busy with their phones and not taking any responsibility. Who gets to do my responsibilities if I got busy with one, like my children? ..." (a male participant,70, in control group).

Four keywords were identified related to pleasure (seems fun, good hobby, easy to communicate and finding new friends). The majority of the participants in both groups, directly and/or indirectly, mentioned the fun aspect of social apps. However, some participants believed that it is not always a good hobby because all kinds of information, video and photos are easily accessible on social networks.

"My children read me some of the posts sent to them [in social network apps]. Sometimes funny or educational ones. I think it is fun and interesting..." (male participant,67, intervention group).

"Some of my peers from family and friends use it [social network app(s)]. I don't feel good when we get together. Either they read new stuffs (posts) or they send it to each other" (male participant,66, intervention group).

“..., I feel like I'm living in another world. Everyone talks about what they read or see [in social network apps] and I just watch them" (male participant,71, control group).

Finally, new experience, being more up-to-date and new opportunities were the keywords related to self-realization. Participants mostly had positive viewpoints regarding the effects of social network apps on self-realization.

"The world has changed a lot since our youth. When we were teenagers, if someone told us you could send photos and videos to someone [living] on the other side of the world immediately, we thought she/he was ridiculous or crazy. But now these things have become as normal as they always have existed. I think it's a new experience and opportunity for our age too......". (male participant,65, intervention group). 
"You can't fight anything new. I like to learn. Why not? It looks like all the people are getting information and news from here [social networks and communication apps] ....." (female participant, 68, control group).

Table 3. The number of repetitions of each code before the educational period between intervention $(\mathrm{n}=10)$ and control $(\mathrm{n}=10)$ groups

\begin{tabular}{|c|c|c|c|c|c|c|}
\hline Themes & Codes & \begin{tabular}{|} 
Interventio \\
n (n)
\end{tabular} & $\begin{array}{c}\text { Intervention } \\
(\%)\end{array}$ & Control (n) & Control (\%) & \begin{tabular}{|c|} 
Intervention- \\
Control \\
difference \\
\end{tabular} \\
\hline \multirow{6}{*}{ Control } & $\begin{array}{l}\text { Age and time } \\
\text { limitation }\end{array}$ & 10 & 100 & 10 & 100 & 0 \\
\hline & $\begin{array}{l}\text { Complicated to } \\
\text { learn }\end{array}$ & 6 & 60 & 4 & 40 & -20 \\
\hline & Physical issues & 5 & 50 & 7 & 70 & +20 \\
\hline & Slow learning & 5 & 50 & 6 & 60 & +10 \\
\hline & Cultural issues & 8 & 80 & 6 & 60 & -20 \\
\hline & Better control & 7 & 70 & 6 & 60 & -10 \\
\hline \multirow{7}{*}{ Autonomy } & Age limitation & 4 & 40 & 5 & 50 & +10 \\
\hline & $\begin{array}{l}\text { No one to learn } \\
\text { from }\end{array}$ & 6 & 60 & 4 & 40 & -20 \\
\hline & Budget limitation & 4 & 40 & 5 & 50 & +10 \\
\hline & Better integration & 8 & 80 & 7 & 70 & -10 \\
\hline & Physical issues & 7 & 70 & 6 & 60 & -10 \\
\hline & $\begin{array}{l}\text { feeling more } \\
\text { independent }\end{array}$ & 6 & 60 & 6 & 60 & 0 \\
\hline & $\begin{array}{l}\text { Reaction of } \\
\text { Family }\end{array}$ & 5 & 50 & 5 & 50 & 0 \\
\hline \multirow[t]{2}{*}{ Pleasure } & \begin{tabular}{|l} 
Easy to \\
commutate
\end{tabular} & 9 & 90 & 10 & 100 & +10 \\
\hline & Seems fun & 8 & 80 & 9 & 90 & +10 \\
\hline \multirow{3}{*}{$\begin{array}{l}\text { Self- } \\
\text { realization }\end{array}$} & New opportunity & 3 & 30 & 4 & 40 & +10 \\
\hline & New experience & 1 & 10 & 4 & 40 & +30 \\
\hline & More up-to-date & 4 & 40 & 0 & 0 & -40 \\
\hline
\end{tabular}

Table 3 represents the number of repetitions of each code before the educational period between intervention $(n=10)$ and control $(n=10)$ groups.

\subsection{Post-test interview analysis}

After finishing the intervention sessions, the same interviewees participating in the pre-test interviews were invited to join the post-test interviews. Of 20 participants in the intervention and control groups in the pre-test interviews, nine and seven participants in intervention and control groups, respectively, participated in the post-test interviews. Similar terms and keywords were extracted in the post-test to allow comparisons between the statements provided by the participants in pre- and post-test. However, the participants' statements in post-post were also searched for new terms and keywords. 
Theme A: Personal consideration in intervention group

Personal consideration of using smart phone apps among the participants in the intervention group had a visible change in the post-test interviews compared with the viewpoints among the interviews in the pre-test. The participants were asked to point any changes they noticed in their viewpoints regarding to personal consideration. The majority of the participants mentioned overall improvement during the post-test interviews. Some of the participants' statements are:

"It was not too hard, even for someone as slow learner as me. At least it wasn't as hard as I thought ..." (a male participant,67, intervention group)

"One of my biggest problems [regarding to using the smart phone communication apps] was vision problems. Now I know how to enlarge texts to make them easier to read. I even change colours to read better. And you know what is the best part? I can do this without the help of my children..." (female participant, 69, intervention group).

Table 4. The number of repetitions of each code after the educational period between intervention $(n=9)$ and control $(n=7)$ groups

\begin{tabular}{|c|l|c|c|c|c|}
\hline$\#$ & \multicolumn{1}{|c|}{ Codes } & Intervention(n) & Intervention(\%) & Control(n) & Control (\%) \\
\hline 1 & Age limitation & 3 & $33 \%$ & 7 & $100 \%$ \\
\hline 2 & Complicated to learn & 2 & $22 \%$ & 5 & $71 \%$ \\
\hline 3 & Physical issues & 4 & $44 \%$ & 3 & $43 \%$ \\
\hline 4 & Slow learning & 1 & $11 \%$ & 2 & $29 \%$ \\
\hline 5 & Cultural issues & 3 & $33 \%$ & 5 & $71 \%$ \\
\hline 6 & Time limitation & 3 & $33 \%$ & 2 & $29 \%$ \\
\hline 7 & No one to learn from & 0 & $0 \%$ & 4 & $57 \%$ \\
\hline 8 & Expansive & 3 & $33 \%$ & 1 & $14 \%$ \\
\hline 9 & Better integration & 7 & $78 \%$ & 5 & $71 \%$ \\
\hline 10 & Better control & 6 & $67 \%$ & 4 & $57 \%$ \\
\hline 11 & feeling more useful & 9 & $100 \%$ & 5 & $71 \%$ \\
\hline 12 & Reaction of Family & 6 & $67 \%$ & 5 & $71 \%$ \\
\hline 13 & Easy to commutate & 9 & $100 \%$ & 7 & $100 \%$ \\
\hline 14 & Seems fun & 8 & $89 \%$ & 6 & $86 \%$ \\
\hline 15 & New experience & 9 & $100 \%$ & 3 & $43 \%$ \\
\hline 16 & More up to date & 9 & $100 \%$ & 3 & $43 \%$ \\
\hline 17 & Informing about news & 8 & $89 \%$ & 0 & $0 \%$ \\
\hline 18 & Less bored & 7 & $78 \%$ & 0 & $0 \%$ \\
\hline
\end{tabular}

However, some participants mentioned that some of their personal consideration still exist. Because their problem was not such that the training course be able to solve it:

"Well, my hands still shake. Still, typing texts takes a lot of time. However, I have learnt ways to be more comfortable. I know that instead of typing I can record my voice. Of course, I still need to practice. Sometimes I do wrong......" (male participant, 71, intervention group).

Theme B and C: Social consideration in pre-test (intervention group)

Along with personal consideration, participants were also asked to talk about any change in family and community issues. This part of the discussion also showed en- 
hancement compared to the pre-test discussions and statements, especially in the statements related to family considerations. Below are examples of interviewees' responses to this.

"Now I can talk to my grandchildren every day. I also can see them through video call. They send me their pictures and I reply them with stickers (emojis). However, sometimes I send a sticker by mistake and they make jokes and laugh. I used to talk to them through telegram [app] sometimes, but I needed my sons help. Now I contact them whenever I miss them......" (female participant,68, intervention group).

"I thought it is better to leave them [communication apps] to younger ones. I still think that it is more attractive to young people. But now I join some groups in telegram and sometimes they send some posts that are even good for me......" (male participant, 69 , intervention group).

"I am still not confident about viewpoints of my relevant about using Instagram, but I have an account anyway, just following the pages close to my interests such as cooking and confectionery. I still don't like to share any picture......" (male participant,69, intervention group).

"I showed to my husband some religious groups that I can join. He is still not so OK with me having an account. He even emphasized it when I wanted to join the educational sessions. At this age, your beliefs cannot be changed........." (female participant, 65 , intervention group).

Table 4 shows the repetitions of each code after the educational period between intervention $(\mathrm{n}=9)$ and control $(\mathrm{n}=7)$ groups. Furthermore, Table 5 compares the final codes and their repetitions in intervention group before $(n=10)$ and after $(n=9)$ the educational period.

Analysing statements based on CASP-19 questionnaire domains (control, autonomy, pleasure and self-realization) among intervention groups: The participants' statements in the post-test were reviewed once again, this time considering the quality-of-life domains based on CASP-19 questionnaire including control, autonomy, pleasure and self-realization. The same keywords, compared to pre-test (age limitation, complicated to learn, physical issues, slow learning, better control to life activities) were searched related to the control concept. Along with previous examples related to these terms, the following statements from the participants also represent more perspective of their viewpoints:

"In our age, it feels good to do something independently, without the need for younger people. Especially when there is something, they [younger people] think they are the only ones knowing that. ......" (a male participant, 69, in intervention group).

"Many of the previous restrictions still exist. But once you know you need something all the time, you can do very well......" (a female participant, 65, intervention group).

Age limitation, time limitation, expensive instrument and cultural issues were the keywords related to autonomy. Furthermore, three keywords were identified related to pleasure (seems fun, good hobby, finding new friends and easy to communicate). With regards to autonomy, the statements below could represent the appropriate examples to clear the viewpoints of the participants in pre-test interviews: 
"Learning along with others of my age was so good that I realized people don't have a bad impression of a woman at my age having an account in Instagram. I was very worried about this before....." (a female participant, 68, intervention group).

"The first few days took a lot of time, but now I don't have that problem. I set my time and get everything done......" (a male participant, 70, intervention group).

Four keywords were identified related to pleasure (seems fun, good hobby, easy to communicate and finding new friends). Majority of the participants in the intervention group mentioned the pleasure advantages of using communication apps. In fact, change in using the keywords related to pleasure was highlighted in the post-test interviews among participants in the intervention group.

"A friend of mine invited me to a group where all members were at my own age. We were posting together, and I became friends with two people living in my city. For me, it's a fun and useful hobby......" (a male participant, 67, intervention group).

"I have learned a lot of new stuff. I have also subscribed in some of the pages with my favourite topics and read them daily. Some, even for me with many years of life experience, look new and fun......" (a male participant, 66, intervention group).

"Now, when everyone is talking about new things they've seen or read [from the communication apps], I also have something to say and don't need to be just a listener....." (a female participant, 68, intervention group).

Finally, new experience, being more up-to-date and new opportunities were the keywords related to self-realization. Participants mostly had positive viewpoints regarding the effects of social network apps on self-realization.

"These days you can't get all the news and information through television or newspapers. It looks like a lot of news come out of these [the communication apps] ......" (a male participant, 65, intervention group).

"Compared to previous, I handle the content faster and easier. Well, some of the stuff here is nowhere to be found that quickly......" (a female participant, 65, intervention group).

Analysing the post-test data for core questions (control group): Only 7 out of 10 participants in control group joined the interviews in post-test. Reviewing the participants' statements in the post-test showed no considerable difference in the keywords extracting, compared to the pre-test keyword. Age limitations still were the most important issues mentioned by the participants. The consistency of the results was quite reasonable given the absence of any intervention and the relatively short interval between pre-test and post-test interviews among the participants in control group. 
Table 5. Comparing the final codes and their number of repetitions in intervention group before $(n=10)$ and after $(n=9)$ the educational period

\begin{tabular}{|c|l|c|c|c|c|c|}
\hline$\#$ & \multicolumn{1}{|c|}{ Codes } & Before (n) & Before (\%) & After (n) & After (\%) & $\begin{array}{c}\text { After-Before } \\
\text { Difference } \\
\text { (\%) }\end{array}$ \\
\hline 1 & Age limitation & 10 & $100 \%$ & 3 & $33 \%$ & -67 \\
\hline 2 & Complicated to learn & 6 & $60 \%$ & 2 & $22 \%$ & -38 \\
\hline 3 & Physical issues & 5 & $50 \%$ & 4 & $44 \%$ & -6 \\
\hline 4 & Slow learning & 5 & $50 \%$ & 1 & $11 \%$ & -39 \\
\hline 5 & Cultural issues & 8 & $80 \%$ & 3 & $33 \%$ & -47 \\
\hline 6 & Time limitation & 4 & $40 \%$ & 3 & $33 \%$ & -7 \\
\hline 7 & No one to learn from & 6 & $60 \%$ & 0 & $0 \%$ & -60 \\
\hline 8 & Expansive & 4 & $40 \%$ & 3 & $33 \%$ & -7 \\
\hline 9 & Better integration & 6 & $60 \%$ & 7 & $78 \%$ & +18 \\
\hline 10 & Better control & 5 & $50 \%$ & 6 & $67 \%$ & +17 \\
\hline 11 & feeling more useful & 6 & $60 \%$ & 9 & $100 \%$ & +40 \\
\hline 12 & Reaction of Family & 5 & $50 \%$ & 6 & $67 \%$ & +17 \\
\hline 13 & Easy to commutate & 9 & $90 \%$ & 9 & $100 \%$ & +10 \\
\hline 14 & Seems fun & 8 & $80 \%$ & 8 & $89 \%$ & +9 \\
\hline 15 & New experience & 1 & $10 \%$ & 9 & $100 \%$ & +90 \\
\hline 16 & More up to date & 4 & $40 \%$ & 9 & $100 \%$ & +60 \\
\hline 17 & Informing about news & 0 & $0 \%$ & 8 & $89 \%$ & +89 \\
\hline 18 & Less bored & 0 & $0 \%$ & 7 & $78 \%$ & +78 \\
\hline
\end{tabular}

Table 6. The final codes and their repetitions in control group before $(n=10)$ and after $(n=7)$ the educational period

\begin{tabular}{|c|l|c|c|c|c|c|}
\hline$\#$ & \multicolumn{1}{|c|}{ Codes } & Before (n) & Before (\%) & After (n) & After (\%) & $\begin{array}{c}\text { Before-After } \\
\text { Difference (\%) }\end{array}$ \\
\hline 1 & Age limitation & 10 & $100 \%$ & 7 & $100 \%$ & $0 \%$ \\
\hline 2 & Complicated to learn & 6 & $60 \%$ & 5 & $71 \%$ & $11 \%$ \\
\hline 3 & Physical issues & 5 & $50 \%$ & 3 & $43 \%$ & $-7 \%$ \\
\hline 4 & Slow learning & 5 & $50 \%$ & 2 & $29 \%$ & $-21 \%$ \\
\hline 5 & Cultural issues & 8 & $80 \%$ & 5 & $71 \%$ & $-9 \%$ \\
\hline 6 & Time limitation & 4 & $40 \%$ & 2 & $29 \%$ & $-11 \%$ \\
\hline 7 & No one to learn from & 6 & $60 \%$ & 4 & $57 \%$ & $-3 \%$ \\
\hline 8 & Expansive & 4 & $40 \%$ & 1 & $14 \%$ & $-26 \%$ \\
\hline 9 & Better integration & 6 & $60 \%$ & 5 & $71 \%$ & $11 \%$ \\
\hline 10 & Better control & 5 & $50 \%$ & 4 & $57 \%$ & $7 \%$ \\
\hline 11 & feeling more useful & 6 & $60 \%$ & 5 & $71 \%$ & $11 \%$ \\
\hline 12 & Reaction of Family & 5 & $50 \%$ & 5 & $71 \%$ & $21 \%$ \\
\hline 13 & Easy to commutate & 9 & $90 \%$ & 7 & $100 \%$ & $-10 \%$ \\
\hline 14 & Seems fun & 8 & $80 \%$ & 6 & $86 \%$ & $-6 \%$ \\
\hline 15 & New experience & 1 & $10 \%$ & 3 & $43 \%$ & $33 \%$ \\
\hline 16 & More up to date & 4 & $40 \%$ & 3 & $43 \%$ & $3 \%$ \\
\hline
\end{tabular}




\section{Discussion}

The effect of online technologies including smartphones and communication applications on lifestyle, quality of life and well-being among elderly have recently become a major issue of attention, increasing research consideration. Using a qualitative method, the current study focused on the effects of using smartphone's communication apps (including Telegram, WhatsApp, and Instagram) in an interventional educational package to determine if increased education improved the quality of life of elderly citizens in Shiraz-Iran.

Participants mostly mentioned that one of their family members (typically one of their children) has chosen/bought their smartphone for them. This was an expected answer due to the age of the participants, semi-traditional culture of Iranian families and because most of the Iranian youth are quite familiar with smartphone technology and criteria of selecting a good smartphone for any purpose. The participants also asked about what they know about communication apps. Participants' responses to this question indicated that some of them were unaware of mobile apps. Some participants also considered the use of these applications as a serious risk to traditional and religious beliefs of families, especially young people, given their traditional beliefs. These answers could also be justified by the Iranian culture. The source of news and information of many of the Iranian elderly is television programmes. Due to the traditional religious context of Iranian society, there is a hidden resistance to the introduction of new technologies among traditional groups, especially the elderly. This resistance is mainly due to concerns about the influence of foreign cultures.

A group of the interviewees in both intervention and control group believed that this technology could be useful and even fun if used correctly. Along with these two options, some participants believed that the tool might be helpful and harmful, but because they did not know how to do it, they were not sure. Participants mentioned directly and indirectly. The family background (traditional or modern), religious beliefs, as well as the number and gender of young people living at home, influenced their view of mobile apps (specifically social apps).

The majority of the respondents pointed to the Telegram app as the app that they have already knew or heard about more, these was also expected because the Telegram app is the most well-known social media app in Iran. Instagram and WhatsApp came in second and third, respectively. Both of these apps are also so familiar in Iran especially among youth [21]

In Iran both Telegram and Instagram applications are used for business (for example online marketing and selling), advertising and entertainment activities. While WhatsApp mostly is a popular alternative for Telegram application and group chats.

The majority of the participants indicated that they think utilizing new technologies such as smartphone apps is late for their age. They mostly pointed to different physical age limitation as an excuse for not using apps. However, as the discussions continued, many participants expressed their interest to use smart phone apps despite their limitations. They believed that using smart phone apps may increase their selfconfidence. 
Despite all the fundamental changes in people's attitudes regarding smartphone technology, there is still a dual approach to this technology in many areas of Iran, especially in smaller cities. While it is unthinkable for the majority of Iranian youth to live without the relatively new technology of smartphones, the use of this technology for seniors still faces resistance due to their traditional beliefs and the usual limitations of aging. These deterrent beliefs are in many cases reinforced by the younger people. This may explain why some participants mentioned that no one in their family has time to teach them how to use the apps by details which has led them to stop trying to learn.

Analysis of the participants' statements in the pre-test, five keywords (age limitation, complicated to learn, physical issues, slow learning, better control to life activities) were identified as the closest ones to the control concept; age limitation, time limitation, expensive instrument and cultural issues were also the keywords found as the related keywords to autonomy. Moreover, four keywords were identified related to pleasure (seems fun, good hobby, easy to communicate and finding new friends). The majority of the participants in both groups, directly and/or indirectly, mentioned the fun aspect of social apps. However, some participants (less than 20\%) believed that it is not always a good hobby because all kinds of information, video and photos are easily accessible on social networks. Finally, new experience, being more up-todate and new opportunities were the keywords related to self-realization. Participants mostly had positive viewpoints regarding the effects of social network apps on selfrealization.

Similar terms and keywords were extracted from the participants' statements at the post-test stage to provide comparisons between pre- and post-test results. Along with the keywords and terms from pre-test, new terms and keywords also were searched from participants' statements in post-test. For example, the terms "informing about news" and "less bored" was not detected from the pre-test statements, while these terms used respectively by $89 \%$ and $78 \%$ of participants in the post-test (intervention group).

As it is clear, most of the participants mentioned some enhancement in their personal and social considerations, as well as the main factors related to their QoL (based on CASP-19 categorization) including control, autonomy, pleasure and selfrealization during the post-test interviews. However, some participants mentioned that some of their personal consideration such as age-related physical limitations still exist. These kinds of problem were not something that the training course could solve. So, it was logical that, given the type of intervention, no change was made in the participants' physical conditions and limitations. However, appropriate training for participants' specific circumstances (e.g., using bold or coloured fonts when typing) somewhat reduced physical constraints.

At the next step of data analysis, the participants' statements in the post-test were analysed again, this time considering the CASP-19 questionnaire domains (control, autonomy, pleasure and self-realization). Same as the pre-test, age limitation, complicated to learn, physical issues, slow learning, and better control to life activities were the keywords related to the control subscale. Moreover, age limitation, time limitation, expensive instrument and cultural issues were the keywords related to autonomy. 
Seems fun, good hobby, finding new friends and easy to communicate are the keywords were detected related to pleasure. Majority of the participants in the intervention group mentioned the pleasure advantages of using communication apps. In fact, change in using the keywords related to pleasure was highlighted in the post-test interviews among participants in the intervention group. Learning the easy ways to use this apps seems to improve participants' perceptions of their difficulties and complexities.

As a result, the entertainment aspect was further enhanced from the participants viewpoint. Finally, new experiences, being more up-to-date and new opportunities were the keywords related to self-realization. Participants mostly had positive viewpoints regarding the effects of social network apps on self-realization.

On the other hand, the situation was quite different among the participants in the control group. Analysing data from the participants in the control group in the posttest did not show any notable difference in the keywords extracting, compared to the pre-test results. In the post test, participants still mentioned age limitations as the most important issues limiting their desire and ability regarding using the smartphone apps. This results consistency was logical and predictable due to the absence of any education and the relatively short interval between pre-test and post-test interviews among the participants in control group.

The findings of the current study are in line with some of the recent relevant studies in different countries. Overall, our study showed using internet/social app via smartphone had a positive effect of on the participant's quality of life.

Reviewing the related study in the last decade, revealed more support on the current study findings. For example, in developed countries, the outcomes of the studies by Winstead et al. [13], Hutto and Bell [22], Bell et al [23], all in the USA, Blažun et. al. [14] in Finland, Erickson J and Johnson GM [24],in Canada and Aarts et al [25] in Netherlands are in line with the outcomes of the current study [13, 22, 26-30] . All these studies have approved the positive effects of different aspects of the ICT of the elderly health and quality of life. In the Winstead et al. [13]

study for instance, not only both studies approved the positive effects of ICT training on the elderly QoL, but even in details, they got same results [13].

Both studies approved the effects of their ICT training positively effects on the participants social relationships.

Regarding age limitation factor, the study current study and the study by Blažun et. al. [14], both reached to same conclusion which "age-related problems" are the significant barrier in learning and using ICT technology including communication and social programs. Meanwhile, both studies also pointed the importance of learning and using the technology due to its positive impacts on loneliness/social relationship and most importantly the participants' QoL[28].

Among the developing countries, reviewing the literatures in Iran, revealed some more evidence sporting the finding of the current study. In Iran, a cross-sectional study by Bahramnezhad et al.[31] and a qualitative study by Momeni et al. [32] showed a direct significant relationship between social network and QoL among the elderly who participated in the study which approve the results of the main findings of the current study[33]. Moreover, the outcomes of all three studies showed high prices 
of the updated smartphones/tablets/personal commuter was one of the limitations of using online social networks among older age in Iran [32]..In addition, these studies indicated the elderly needs to learn some of the basic concepts to help them access to the useful webpages and applications. Therefore, having specific knowledge is important for the use of social media. So, the needs of educational courses for the elderly for receiving basic knowledge to use computers, internet, and subsequently social networks is necessary. Iranian elderly should be encouraged to use the social networks to improve their adaptation with the today modern life and improve their quality of life.

However, not all the findings of previous studies are in line with the outcomes of the current study. For example, according to the findings of study by Khalaila \& Vitman-Schorr in 2018 [34].

Although use of Internet and social media/apps can improve the level of quality of life among older adults both directly and indirectly (mostly due to decreasing loneliness and improving independence), these influences could be dependent on other factors. For example, the indirect impact could be moderated by ethnicity. As well, these effects could be directly affected by the time that elderly spend with their families [34].

Despite all the fundamental changes in people's attitudes regarding smartphone technology, there is still different viewpoints regarding this technology in many areas of Iran, especially in smaller cities. In another counterexample, using of social media showed no effects (positive or negative) among the elderly regarding their daily function, and emotional well-being were investigated in an experimental study by Slegers et al. in Netherlands [35].

Keeping all above discussions in mind, the most significant gap this study tried to address was the absence of studies about the effect of using internet and social/communication apps on the Iranian elderly quality of life. Even in the recent years the studies on this topic have increased significantly, there are very few data and information in Iranian elderly population. In fact, most of the related studies was done in developed countries which highlights the importance of delivering basic and essential skills on using internet and online social networks. Many of these studies, as we discussed, have approved the positive effects of using online technology on elderly life, in both developing and developed countries.

Therefore, due to the importance and magnitude of improving QoL of older adults in community, the findings of this study and the educational training are intended to help families, practitioners in the aging field to pay more attention to teaching modern communication technology in order to promote healthier elderly and community. Studies on bigger samples, different devices/applications as well as different studies with different methods are recommended for future works.

\section{$5 \quad$ References}

[1] Hosseini, S.E. and K. Goher, Personal care robots for older adults: An overview. Asian Social Science, 2017. 13. https://doi.org/10.5539/ass.v13n1p11 
[2] Mansouri, N., K. Goher, and S.E. Hosseini, Ethical framework of assistive devices: review and reflection. Robotics and Biomimetics, 2017. 4(1): p. 19. https://doi.org/10.1186/s406 $\underline{38-017-0074-2}$

[3] Saare, M., A. Hussain, and W.S. Yue, Investigating the effectiveness of mobile peer support to enhance the quality of life of older adults: a systematic literature review. 2019. 13(4). https://doi.org/10.3991/ijim.v13i04.10525

[4] Sanfilippo, F. and C. Pacchierotti, A wearable haptic system for the health monitoring of elderly people in smart cities. International Journal of Online Engineering, 2018. 14(8): p. 1-15. https://doi.org/10.3991/ijoe.v14i08.8571

[5] Hedayati, H.R., et al., Quality of life among nursing home residents compared with the elderly at home. Shiraz E-Medical Journal, 2014. 15(4). https://doi.org/10.17795/semj22718

[6] Khazaei Jalil, S., et al., Quality of life among Elderly Living at Nursing Home in Shahroud city. Iranian Journal of Geriatric Nursing, 2015. 2(1): p. 39-49.

[7] Hosseini, S.E. and K. Goher, Personal care robots for children: state of the art. Asian Social Science 2017. 13(1). https://doi.org/10.5539/ass.v13n1p169

[8] Hosseini, S.E., A.A. Ramchahi, and R.J.R. Yusuf, The impact of information technology on Islamic behaviour. Journal of Multidisciplinary Engineering Science and Technology (JMEST), 2014. 1(5): p. 135-141.

[9] Hosseini, S.E., E. Kaed, and A. Alhazmi, Acquiring knowledge through mobile applications. International Journal of Interactive Mobile Technologies (iJIM), 2015. 9(3): p. 7174. https://doi.org/10.3991/ijim.v9i3.4495

[10] New technologies are more useful for seniors. 2017 08.04.2018]; Available from: https://www.eghtesadonline.com/.

[11] Saboor, M., et al., The Internet Use in Elderly People Medicinski Glasnik/Medical Gazette, 2015. 20(56).

[12] Etikan, I., S.A. Musa, and R.S. Alkassim, Comparison of convenience sampling and purposive sampling. American Journal of Theoretical and Applied Statistics, 2016. 5(1): p. 14. https://doi.org/10.11648/j.ajtas.20160501.11

[13] Winstead, V., et al., You can teach an old dog new tricks: A qualitative analysis of how residents of senior living communities may use the web to overcome spatial and social barriers. Journal of Applied Gerontology, 2013. 32(5): p. 540-560. https://doi.org/10.1177/ 0733464811431824

[14] Blažun, H. and Saranto, Impact of computer training courses on reduction of loneliness of older people in Finland and Slovenia. Computers in Human Behavior, 2012. 28(4): p. 1202-1212. https://doi.org/10.1016/j.chb.2012.02.004

[15] Sitti, S. and S. Nuntachampoo, Attitudes towards the use of ICT training curriculum for Thai elderly people. Procedia-Social and Behavioral Sciences, 2013. 103: p. 161-164. https://doi.org/10.1016/j.sbspro.2013.10.321

[16] Navabi, N., F. Ghaffari, and Z. Jannat-Alipoor, Older adults' attitudes and barriers toward the use of mobile phones. Clinical interventions in aging, 2016. 11: p. 1371. https://doi. org/10.2147/cia.s112893

[17] Ayres, L., K. Kavanaugh, and K.A. Knafl, Within-case and across-case approaches to qualitative data analysis. Qualitative health research, 2003. 13(6): p. 871-883. https://doi. org/10.1177/1049732303013006008

[18] Lincoln, Y.S. and E. Guba, Qualitative inquiry. Thousand Oaks, 1985.

[19] Thomas, D.R., A general inductive approach for analyzing qualitative evaluation data. American journal of evaluation, 2006. 27(2): p. 237-246. https://doi.org/10.1177/10982140 $\underline{05283748}$

[20] Strauss, A. and J. Corbin, Basics of qualitative research. 1990: Sage publications. 
[21] Nikkhah, M., et al., Psychometric properties the Iranian version of Older People's Quality Of Life questionnaire (OPQOL). Health and quality of life outcomes, 2018. 16(1): p. 174. https://doi.org/10.1186/s12955-018-1002-Z

[22] Hutto, C. and C. Bell. Social media gerontology: Understanding social media usage among a unique and expanding community of users. in 2014 47th Hawaii International Conference on System Sciences. 2014. IEEE. https://doi.org/10.1109/hicss.2014.223

[23] Bell, C. and Fausset. Examining social media use among older adults. in Proceedings of the 24th ACM conference on hypertext and social media. 2013. ACM. https://doi.org/10. $\underline{1145 / 2481492.2481509}$

[24] Erickson and Genevieve, Internet use and psychological wellness during late adulthood. Canadian Journal on Aging/la Revue canadienne du vieillissement, 2011. 30(2): p. 197209. https://doi.org/10.1017/s0714980811000109

[25] Aarts and Peek, The relation between social network site usage and loneliness and mental health in community-dwelling older adults. International journal of geriatric psychiatry, 2015. 30(9): p. 942-949. https://doi.org/10.1002/gps.4241

[26] Aarts, S., S. Peek, and E.J.I.j.o.g.p. Wouters, The relation between social network site usage and loneliness and mental health in community-dwelling older adults. 2015. 30(9): p. 942-949. https://doi.org/10.1002/gps.4241

[27] Bell, C., et al. Examining social media use among older adults. in Proceedings of the 24th ACM conference on hypertext and social media. 2013. https://doi.org/10.1145/2481492. 2481509

[28] Blažun, H., K. Saranto, and S.J.C.i.H.B. Rissanen, Impact of computer training courses on reduction of loneliness of older people in Finland and Slovenia. 2012. 28(4): p. 1202-1212. https://doi.org/10.1016/j.chb.2012.02.004

[29] Cotten, S.R., W.A. Anderson, and B.M. McCullough, Impact of internet use on loneliness and contact with others among older adults: cross-sectional analysis. Journal of medical Internet research, 2013. 15(2). https://doi.org/10.2196/jmir.2306

[30] Erickson, J. and G.M.J.C.J.o.A.1.R.c.d.v. Johnson, Internet use and psychological wellness during late adulthood. 2011. 30(2): p. 197-209. https://doi.org/10.1017/s0714980811000 $\underline{109}$

[31] Bahramnezhad, F., et al., The social network among the elderly and its relationship with quality of life. Electronic physician, 2017. 9(5): p. 4306. https://doi.org/10.19082/4306

[32] Momeni, M., et al., Barriers and challenges experienced by seniors in using online social networks: a phenomenological study. Middle East Journal of Rehabilitation and Health, 2018. 5(1). https://doi.org/10.5812/mejrh.65310

[33] Bahramnezhad, F., et al., The social network among the elderly and its relationship with quality of life. 2017. 9(5): p. 4306.

[34] Khalaila, R. and A. Vitman-Schorr, Internet use, social networks, loneliness, and quality of life among adults aged 50 and older: mediating and moderating effects. Quality of Life Research, 2018. 27(2): p. 479-489. https://doi.org/10.1007/s11136-017-1749-4

[35] Slegers, K., M.P. Van Boxtel, and J. Jolles, Effects of computer training and Internet usage on the well-being and quality of life of older adults: A randomized, controlled study. The journals of gerontology series B: Psychological sciences and social sciences, 2008. 63(3): p. P176-P184. https://doi.org/10.1093/geronb/63.3.p176 


\section{Authors}

Seyed Ebrahim Hosseini is a Senior Lecturer at Abacus Institute of Studies and a $\mathrm{PhD}$ candidate at Lincoln University New Zealand. His research revolves around people and technology, and its applications in learning and e-learning.

Stuart Charters is a Senior Lecturer. At Lincoln University. His research is focused on the interface between people and technology including the human aspects of Software Engineering and communicating information through visualization.

Patricia Anthony is an Associate Professor at Lincoln University, New Zealand. Her research revolves around agent and multi-agent systems, machine learning, sentiment analysis and emotion identification in text. She is also interested in utilising artificial intelligence techniques for decision making in various domains such as agriculture, commerce and education.

Abdulsalam K. Alhazmi is a consultant and Researcher in the field of Technology and its applications in e-learning and e-commerce systems.

Currently he is the Deputy Dean of the Faculty of Electronic and Distance Learning at the University of Science and Technology, managing the International Joint and Dual Degree Programs with Malaysian universities. He also works as a Consultant for a few companies in Malaysia specialized in e-learning programs, and smart systems and applications.

Article submitted 2020-11-26. Resubmitted 2021-01-10. Final acceptance 2021-01-14. Final version published as submitted by the authors. 